\title{
Remediation of Aqueous Solution of Cypermethrin and Chlorpyriphos Using Derived Adsorbent from Jatropha Curcas
}

\section{${ }^{* 1}$ OKEOLA, FO; ${ }^{2}$ ODEBUNMI, EO; ${ }^{1}$ NWOSU, FO; ${ }^{1} \mathrm{ABU}, \mathrm{TO} ;{ }^{1}$ IDIAGBONYA, OS; ${ }^{3}$ AMOLOYE, MA; ${ }^{2}$ ONIFADE, FT; ${ }^{4}$ ABDULMUMMEEN, AG}

\author{
${ }^{1}$ Industrial Chemistry Department, University of Ilorin, Ilorin, Nigeria \\ ${ }^{2}$ Chemistry Department, University of Ilorin, Ilorin, Nigeria \\ ${ }^{3}$ Chemical Engineering Department, University of Ilorin, Ilorin, Nigeria \\ ${ }^{4}$ Chemistry Department, Federal University of Technology Minna, Nigeria \\ * Email: okeola.of@unilorin.edu.ng; okeolaf@yahoo.com \\ Phone Number: +2348058749768, +2348038626501
}

\begin{abstract}
The study focused on assessment of removal of cypermethrin and chloropyriphos in aqueous solution using activated carbon made from Jatropha Curcas. Batch adsorption experiments were carried out under different conditions of parameters such as $\mathrm{pH}$, contact time, adsorbent dosage, and initial concentration of the adsorbate on pesticide adsorption. The adsorption data were described by Langmuir and Freundlich adsorption model. Adsorption capacity of $92.73 \%$ and $92.26 \%$ of chloropyriphos and cypermetrin respectively were removed by $2 \mathrm{~g}$ of the adsorbent per $50 \mathrm{~cm}^{3}$ of initial concentration of $0.78 \mathrm{mg} / \mathrm{l}$ and $1.50 \mathrm{mg} / \mathrm{l}$ chloropyriphos and cypermetrin respectively. This was achieved at $90 \mathrm{~min}$ of the contact time and at optimum $\mathrm{pH}$ of 6.3.The study demonstrates that the activated carbon made from Jatropha Curcas can be effective in the adsorption of these two pesticides from water bodies. Equilibrium experiment results show that adsorption isotherms of cypermethrin and fit better to Freundlich adsorption isotherm while chloropyriphos fit better on the Langmuir adsorption isotherm (C) JASEM
\end{abstract}

http://dx.doi.org/10.4314/jasem.v21i1.5

Key words: remediation, pesticides, Jatropha Curcas, cypermethrin, chloropyriphos, Langmuir and Freundlich equation

Safety in our environment has been the focus of the day. A major factors constituting to enormous threat to environment is pesticides pollution. Pesticides are artificially synthesized, toxic bio accumulative agents. Chemical pesticides are frequently applied in agricultural activities to ensure good harvest (Chang et al, 2011) The ongoing and uncontrolled use of pesticide to fight pest and improve agricultural production constitutes a risk for water quality (Mirjana et al, 2010). The pesticides have been detected by monitoring surface and underground waters. According to European Union Directives and Regulations for drinking water hygiene, the maximum allowed concentration of total pesticides is $0.5 \mu \mathrm{g} \mathrm{dm}^{-3}$ (Mirjana et al, 2010). The problem of chemical pesticides in the environment is a social issue as the contaminant were frequently detected in the different water sources, rivers and soil. The leaching runs off from agricultural forest land \& even residential places. The toxicity of pesticide and their degradation products is making these chemical substances a potential hazard (Salman et al. 2010).

Chloropyriphos (O,O-diethyl O-3,5,6-trichloro-2pyridyl phosphorothioate) is a common organophosphorus insecticide, widely used active ingredient for the protection of important agricultural crops such as corn, citrus, peanuts, etc and also effective in controlling a variety of insects including worms, cockroaches, flies, termites, fire ant and lice. On the other hand Cypermethrin is a pyrethroid pesticide and is used in the control of a wide range of insects on crops like vegetables, cereals and maize (USEPA, 2002).Conventional waste water technologies for treating pesticides wastewater and industrial effluents include chemicals, biological and physical treatments such as coagulation and flocculation,ozonation, electrochemical processes, nano filtration, and adsorption(Okeola et.al,2014; The following conventional methods were used for removal of some pesticides in wastewaters Fenton with coagulation (Chen et al, 2007), photo catalysis and electro-Fenton , combined ultrasound and Fenton (Ma et al, 2010), Oxidants and photolysis, biological degradation (Singh et al, 2008) and adsorption (Ignatowicz , 2009). However, adsorption process is one of the most widely applied techniques for pollutant removal. Adsorption plays a significant role in the environmental pollution control The common adsorbents include activated carbon molecular sieves polymetric adsorbents and some other low cost material.Among numerous clean-up techniques, adsorption technique with activated carbon from agricultural material or waste is ecofriendly. Such sources include bamboo, coconut shell,chestnut shells (Memon et al, 2007) and snail shell (Udeozor and Evbuomwan 2014). Adsorbents derived from jatropha curcas has been used effectively for various 
adsorptions, Raw treatment jatropha curcas was applied for adsorption of aqueous $\mathrm{Cu}$ (II) ion adsorption (Jain et al 2008), activated carbon processed from the shell of this crop has been used for adsorption of methylene blue (Okeola et al 2010), adsorption of Congo red (Okeola et al 2014), Removal of Fe (II) ion (Okeola and Odebunmi 2011).

Therefore this work is to determine the feasibility of application of the activated carbon from jatropha curcas shell for the adsorption of the pesticides cypermethrin and Chloropyriphos Thus reducing or removing them from aqueous environment.

\section{MATERIALS AND METHODS}

Adsorbate and adsorbent: The adsorbent employed is the already produced activated carbon from jatropha curcas shell. This has been used for effective adsorption of methylene blue and acetic acid (organic solutes) and potassium permanganate (inorganic solute).Chloropyriphos and cypermehtrin were procured from an agrochemical plaza along Ilorin,Kwara state, Nigeria. A $100 \mathrm{mg} / \mathrm{L}$ solution of Cypermethrin pesticide was prepared by taking $1 \mathrm{ml}$ of the stock solution $100 \mathrm{~g} / \mathrm{L}$ into $1000 \mathrm{ml}$ standard flask. Subsequent solutions of lower concentration were made by serial dilution.

$a_{a}=\frac{V\left(C_{i}-C_{f}\right)}{w}$
Batch equilibrium studies: Batch adsorption experiments were carried out using a series of erlenmeyer flasks. The experiments were conducted to investigate the effect of $\mathrm{pH}$ contact time,initial pesticide concentration and adsorbent dosage. All the adsorption experiments were carried out at room temperature $\left(30 \pm 2^{\circ} \mathrm{C}\right)$. The initial $\mathrm{pH}$ was adjusted with $0.1 \mathrm{M} \mathrm{HCl}$ or $0.1 \mathrm{M} \mathrm{NaOH}$. Time course experiments were investigated by shaking the sorption mixture of (adsorbent and adsorbate) at various predetermined interval and conditions. The mixtures left were filtered and the filtrate analysed for the adsorbate concentration, blank solutions without adsorbent were also shaken and the concentrations determined. This was used as initial concentration. The concentrations of pesticide in the solution before and after adsorption were determined using a double beam UV-Vis spectrophotometer (Shimadzu DU 730) at its maximum wavelength of $300 \mathrm{~nm}$ and $375 \mathrm{~nm}$ for Chloropyriphos and cypermethrin respectively. Each batch of the experiment were duplicated under identical conditions and the results obtained from their means. In the determination of adsorption capacity of solute intake per unit mass of activated carbon $\left(\mathrm{q}_{\mathrm{e}}, \mathrm{mg} / \mathrm{g}\right)$ was calculated using adsorption system mass balance as shown in equation (i)

Where $\mathrm{v}=$ volume of solution $(\mathrm{L})$

$\mathrm{w}=$ amount of dry adsorbent/ substrate $(\mathrm{g})$

$\mathrm{c}_{\mathrm{i}}=$ initial concentration $(\mathrm{mg} / \mathrm{l})$ and

$\mathrm{c}_{\mathrm{f}}=$ final concentration $(\mathrm{g})$

The percentage of dye uptake (\% uptake) was also calculated in some cases using the equation (ii);

$$
\% \text { uptake }=\frac{c_{1}-c_{f}}{c_{\mathrm{i}}} \times 100
$$

Determination of Effect of adsorbent dosage on chlorpyriphos and cypermetrin: The effect of adsorbent dosage on adsorption of chlorpyriphos and cypermetrin was studied using initial concentration of $0.78 \mathrm{mg} / \mathrm{l}$ and $1.50 \mathrm{mg} / \mathrm{l}$ respectively for different amount of the adsorbent $(0.1,0.2,0.5,1.0,1.5,2.0$, 3.0) g that were separately weighed into different sample bottles. A $50 \mathrm{ml}$ of the same concentration of each of the pesticide solution was added into each sample bottles containing the adsorbent.

Determination of Effect of contact time on chlorpyriphos and cypermetrin: Contact time is an important factor in the efficient solute adsorption. The effect of contact time on the adsorption of each pesticide from aqueous solution on this activated was tested by taking $2.0 \mathrm{~g}$ activated carbon sample with $50 \mathrm{ml}$ of $0.78 \mathrm{mg} / \mathrm{l}$ and $1.50 \mathrm{mg} / \mathrm{l}$ of chlorpyriphos and cypermetrin respectively in $250 \mathrm{ml}$ flask. This was shaken on mechanical shaker at various time intervals between 15-105 mins. The clear solution was analysed for the residual pesticide concentration.

Determination of Effect of $\mathrm{pH}$ on chlorpyriphos and cypermetrin: The $\mathrm{pH}$ of the solution is an important controlling parameter in the adsorption process. The effect of $\mathrm{pH}$ on the equilibrium sorption of each pesticide was investigated by employing an initial concentration of chlorpyriphos and cypermetrin, 0.78 $\mathrm{mg} / \mathrm{l}$ and $1.50 \mathrm{mg} / \mathrm{l}$ respectively and $0.2 \mathrm{~g}$ of activated carbon (TSC) in $50 \mathrm{ml}$ of solution. The suspensions were shaken for $100 \mathrm{~min}$ and the amount of pesticide adsorbed determined. The experiment was repeated for $\mathrm{pH}$ 2.2-7.5.

Determination of Effect of initial concentration on chlorpyriphos and cypermetrin: The effect of initial concentration of chloropyriphos and cypermethrin 
concentration on adsorption was investigated. The experiments were carried out at a fixed dose of activated carbon $(0.2 \mathrm{~g})$, temperature $30^{\circ} \mathrm{C}, \mathrm{pH} 6.3$ and different initial concentration of pesticide, range of $1.5-1.8 \mathrm{mg} / \mathrm{l}$.

Evaluation of Adsorption Isotherm of chlorpyriphos and cypermetrin: The capacity of the adsorption isotherm is fundamental, and plays an important role in the determination of the maximum capacity of adsorption. It also provides a panorama of the course taken by the system under study in a concise form, indicating how efficiently an adsorbent will adsorb and allows an estimate of the economic viability of the adsorbent commercial applications for the specific solute. In order to adapt for the considered system, an adequate model that can produce the experimental results obtained, equations of Langmuir and Freundlich, have been considered. The two models have been the most widely used isotherm equation. Construction of Adsorption Isotherm was carried out from the batch adsorption experiment of effect of initial concentration by adding $0.2 \mathrm{~g}$ fixed dose of activated carbon temperature $30^{\circ} \mathrm{C}, \mathrm{pH} \quad 6.3$ and different initial concentration of pesticide, range of $1.5-1.8 \mathrm{mg} / \mathrm{l}$.

Freundlich Adsorption Isotherm: The Freundlich isotherm model is an empirical relationship describing the adsorption of solutes from a liquid to a solid surface assumes that different sites with several adsorption energies are involved. Freundlich adsorption isotherm is the relationship between the amounts of solute adsorbed per unit mass of adsorbent, $\mathrm{q}_{\mathrm{e}}$, and the concentration of the solute at equilibrium, $\mathrm{C}_{\mathrm{e}}$. This isotherm can be described as in equation (iii)

$\log q_{\theta}=\log K_{f}+\frac{2}{n} \log C_{e}$

Where $q_{\oplus}(\mathrm{mg} / \mathrm{g})$ is the adsorption capacity at equilibrium, $C_{\oplus}(\mathrm{mg} / \mathrm{L})$ is the equilibrium concentration of adsorbate in solution and $K_{f}(\mathrm{mg} / \mathrm{g})$ and $\mathrm{n}$ are the Freundlich physical constants,both are the indicator of the adsorption capacity and adsorption intensity respectively. (Ma et al 2010).

Langmuir Adsorption Isotherm: The Langmuir model is based on the assumption that the maximum adsorption occurs when a saturated monolayer of solute molecules is present on the adsorbent surface, the energy of adsorption is constant and there is no migration of adsorbate molecules in the surface plane. (Kumar and Gayathri 2009 ; Okeola and Odebunmi ,2010) The Langmuir isotherm is given in equation (iv)

$\frac{1}{q_{e}}=\frac{1}{q_{m}}+\frac{1}{q_{m} \mathrm{KL}} \frac{1}{C e}$

Where $\mathrm{q}_{\mathrm{m}}(\mathrm{mg} / \mathrm{g})$ and $\mathrm{KL}(\mathrm{L} / \mathrm{g})$ are the Langmuir constants representing the maximum monolayer adsorption capacity for the solid phase loading and the energy constant related to the heat of adsorption respectively.

\section{RESULTS AND DISCUSSION}

Effect of adsorbent dosage on adsorption of pesticides: In the studies the adsorption percent (\%) of the respective pesticides was found to vary with different mass samples. From data presented in Table1,it shows that the suitable mass of activated carbon is $(2 \mathrm{~g})$. The adsorption percent $92.73 \%$ and
$92.26 \%$ for chloropyriphos and cypermetrin respectively was observed. A similar result was observed for the removal of carbofuran and chloropyriphos from aqueous solution using walnut shells (Memon et al 2007) 


\begin{tabular}{ccccc}
\multicolumn{5}{c}{ Table 1 Percentage adsorption of cypermethrin and chlorpyrophos } \\
Adsorbate \\
mass of adsorbent
\end{tabular}

$\mathrm{pH}=6.3$,time $1.5 \mathrm{hr} \quad$ temp. $30^{\circ} \mathrm{C}$

Effect of contact time on adsorption of chlorpyriphos and cypermetrin: The influence of contact time on adsorption capacity of chlorpyriphos and cypermetrin is shown in table 2 . The results clearly show that the adsorption of chlorpyriphos and cypermetrin increases with time until reaching a nearly saturation level. Rate of uptake of each pesticide is higher at the beginning which may be due availability of a large number of active sites on the adsorbent.As the sites become exhausted the uptake rate depends on transportation from outside to inside the adsorbent particles (Udeozor and Evbuomwan 2014) However, the time of saturation totally equals with chlorpyrifos and cypermetrin. The observation obviosly,shows the specific time of saturation of 90 mins for chlorpyrifos and cypermetrin with adsorption capacity of $92.29 \%$ and $92.78 \%$ respectively.

Table 2. Contact time factor on adsorption capacity and percentage adsorption of cypermethrin and chlorpyrophos

\begin{tabular}{|c|c|c|c|c|c|c|}
\hline \multirow[t]{2}{*}{ Adsorbate } & Time & $\mathrm{Co}(\mathrm{mg} / \mathrm{l})$ & $\mathrm{Ce}(\mathrm{mg} / \mathrm{l})$ & $\mathrm{X}(\mathrm{mg} / \mathrm{l})$ & $\mathrm{Qe}(\mathrm{mg} / \mathrm{g})$ & \% Adsorption \\
\hline & 15 & 1.5 & 1.213 & 0.287 & 7.170 & 19.12 \\
\hline \multirow{6}{*}{ 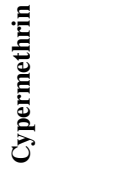 } & 30 & 1.5 & 0.674 & 0.827 & 20.663 & 55.1 \\
\hline & 45 & 1.5 & 0.444 & 1.056 & 26.396 & 70.39 \\
\hline & 60.0 & 1.5 & 0.278 & 1.222 & 30.544 & 81.45 \\
\hline & 75 & 1.5 & 0.119 & 1.381 & 34.519 & 92.05 \\
\hline & 90.0 & 1.5 & 0.116 & 1.384 & 34.609 & 92.29 \\
\hline & 105.0 & 1.5 & 0.116 & 1.384 & 34.609 & 92.29 \\
\hline \multirow{7}{*}{ 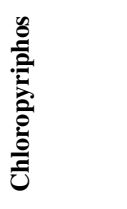 } & 15 & 0.78 & 0.672 & 0.108 & 2.711 & 13.9 \\
\hline & 30 & 0.78 & 0.651 & 0.129 & 3.231 & 16.57 \\
\hline & 45 & 0.78 & 0.544 & 0.236 & 5.899 & 30.25 \\
\hline & 60.0 & 0.78 & 0.145 & 0.635 & 15.877 & 81.42 \\
\hline & 75 & 0.78 & 0.061 & 0.719 & 17.983 & 92.22 \\
\hline & 90.0 & 0.78 & 0.057 & 0.723 & 18.067 & 92.78 \\
\hline & 105.0 & 0.78 & 0.057 & 0.723 & 18.067 & 92.78 \\
\hline
\end{tabular}

Adsorbent dosage $2 \mathrm{~g} / 50 \mathrm{ml} \mathrm{pH} 6.3$ temp. $30^{\circ} \mathrm{C}$

Effect of $\mathrm{pH}$ on adsorption of chlorpyrifos and cypermetrin: The $\mathrm{pH}$ of the solution is an important controlling parameter in the adsorption process. The effect of $\mathrm{pH}$ on the adsorption uptake percent (\%) of chlorpyrifos and cypermetrin is shown in table 3. From these data it is obvious that the percent adsorption gradually increases by increasing the $\mathrm{pH}$ till reaching maximum uptake at $\mathrm{pH}$ of 6.3 . The adsorption percent of the each pesticide show similar trend. Meanwhile, the adsorption is low below pH 4.0 and increases rapidly at $\mathrm{pH} 5.6$ getting to maximum at $\mathrm{pH} 6.3$. At this $\mathrm{pH}$ of $6.3,92.57 \%$ and $92.25 \%$ of chloropyriphos and cypermetrin respectively were adsorbed. At higher $\mathrm{pH}$ the pesticides start degrading. The trend of the results is seen in the removal of carbofuran and chloropyriphos from wastewater using walnut shell (Memon et al 2007) 
Table 3. Effect of $\mathrm{pH}$ on adsorption capacity and percentage adsorption of cypermethrin and chlorpyrophos

\begin{tabular}{|c|c|c|c|c|c|c|}
\hline Adsorbate & $\mathrm{pH}$ & Co (mg/l) & $\mathrm{Ce}(\mathrm{mg} / \mathrm{l})$ & $\mathrm{X}(\mathrm{mg} / \mathrm{l})$ & $\mathrm{Qe}(\mathrm{mg} / \mathrm{g})$ & $\%$ Adsorption \\
\hline \multirow{7}{*}{ 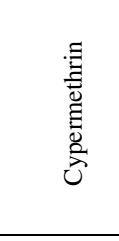 } & 2.2 & 1.5 & 1.360 & 0.140 & 3.499 & 9.33 \\
\hline & 3.1 & 1.5 & 0.972 & 0.528 & 13.193 & 35.18 \\
\hline & 4.1 & 1.5 & 0.529 & 0.971 & 24.285 & 64.76 \\
\hline & 5.6 & 1.5 & 0.158 & 1.342 & 33.544 & 89.45 \\
\hline & 6.3 & 1.5 & 0.116 & 1.384 & 34.594 & 92.25 \\
\hline & 7.1 & 1.5 & 0.149 & 1.351 & 33.776 & 90.07 \\
\hline & 7.5 & 1.5 & 0.245 & 1.255 & 31.365 & 83.64 \\
\hline \multirow{7}{*}{$\begin{array}{l}\frac{8}{0} \\
\frac{d}{2} \\
\frac{1}{2} \\
\frac{2}{0} \\
\frac{0}{0} \\
0\end{array}$} & 2.2 & 0.78 & 0.672 & 0.108 & 2.711 & 11.17 \\
\hline & 3.1 & 0.78 & 0.651 & 0.129 & 3.231 & 46.87 \\
\hline & 4.1 & 0.78 & 0.544 & 0.236 & 5.899 & 62.73 \\
\hline & 5.6 & 0.78 & 0.145 & 0.635 & 15.877 & 88.52 \\
\hline & 6.3 & 0.78 & 0.061 & 0.719 & 17.983 & 92.57 \\
\hline & 7.1 & 0.78 & 0.057 & 0.723 & 18.067 & 89.76 \\
\hline & 7.5 & 0.78 & 0.057 & 0.723 & 18.067 & 84.41 \\
\hline
\end{tabular}

Adsorbent dosage $2 \mathrm{~g} / 50 \mathrm{~m}$ temp. $30^{\circ} \mathrm{C}$

Effect of initial concentration on adsorption: The effect of initial pestide chloropyriphos and cypermethrin concentration in the range of $1.5-1.8$ $\mathrm{mg} / \mathrm{l}$ on adsorption was investigated and is shown in table 4. It is evident that the percentage pesticide removal increased with the increase in initial concentration of the pesticide. The initial pesticide concentration provides the necessary driving force to overcome the resistances to the mass transfer of pesticide between the aqueous phase and the solid phase. The driving force was observed to be greater in cypermethrin in which $\mathrm{q}_{\mathrm{e}}$ (amount of adsorption per unit mass of adsorbent) of $87.5 \mathrm{mg} / \mathrm{g}$ at initial concentration of $8.0 \mathrm{mg} / \mathrm{l}$ from $7.5 \mathrm{mg} / \mathrm{g}$ at initial concentration of $1.5 \mathrm{mg} / \mathrm{l}$. In chlorpyrifos $\mathrm{q}_{\mathrm{e}}$ (amount of adsorption per unit mass of adsorbent) of $37.5 \mathrm{mg} / \mathrm{g}$ at initial concentration of $7.0 \mathrm{mg} / \mathrm{l}$ from $5.0 \mathrm{mg} / \mathrm{g}$ at initial concentration of $1.5 \mathrm{mg} / \mathrm{l}$.

Isotherm Modelling: The adsorption isotherm data for the pesticide adsorption were as prepared in table 4 . The graphical representations of these models are presented in figure 1 for Langmuir and figure 2 for Freundlich isotherm respectively. Each of the pesticide adsorbed per gram, $\left(\mathrm{q}_{\mathrm{e}}\right)$ and respective equilibrium concentration $(\mathrm{Ce})$ for each initial concentration of the pesticide was prepared. The plot of $1 / q_{\mathrm{e}}$ against the $1 / \mathrm{Ce}$ on shows straight lines as displayed in figs. 1. This linear relationship is an indication that the adsorption process fit in and can be described by a Langmuir type isotherm. The fitting to Langmuir shows that the adsorption occurs mainly through the formation of a single monolayer of adsorbed molecules.Chloropyriphos adsorption fit better on Langmuir type isotherm

On the other hand, the plot of $\log \mathrm{q}_{\mathrm{e}}$ against the $\log$ $\mathrm{Ce}$ on shows straight lines as displayed in figs. 2 for cypermethrin and chlorpyrophos respectively this linear relationship is an indication that the adsorption process also fit in and can be described by a Freundlich isotherm. Cypermethrin adsorption was of course observed to fit better on Freundlich type isotherm

The isotherm equation is applied to describe the data in a quantitative way. (Okeola and Odebunmi, 2010). The isotherm parameters and correlation coefficient $\mathrm{R}^{2}$ values are tabulated in table 6 . When the value of correlation co - efficient, $\mathrm{R}^{2}$ is nearer to 1 , the respective experimental data tend to fits better to the respective equation. The values of $\mathrm{n}$ (from Freundlich equation) greater than unity, suggesting favourable adsorption .The result of $\mathrm{q}_{\mathrm{m}}$ (from Langmuir equation) shows an higher adsorption of cypermethrin under the same adsorption factor (Chang et al 2011) 
Table 4: Effect of initial concentration on adsorption and Adsorption isotherm Data

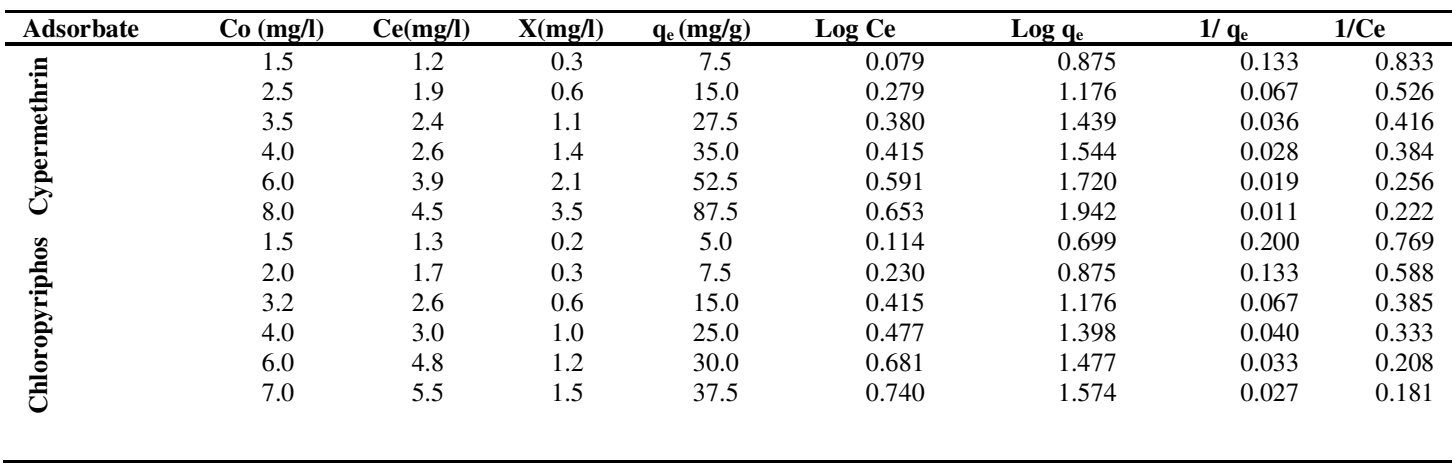

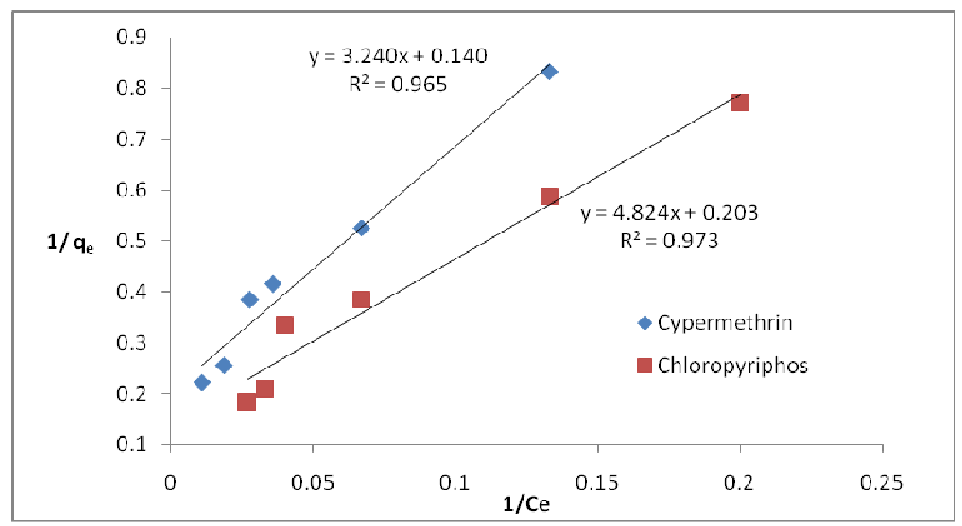

Fig 1: Langmuir adsorption of isotherm of cypermethrin and chloropyriphos adsorption

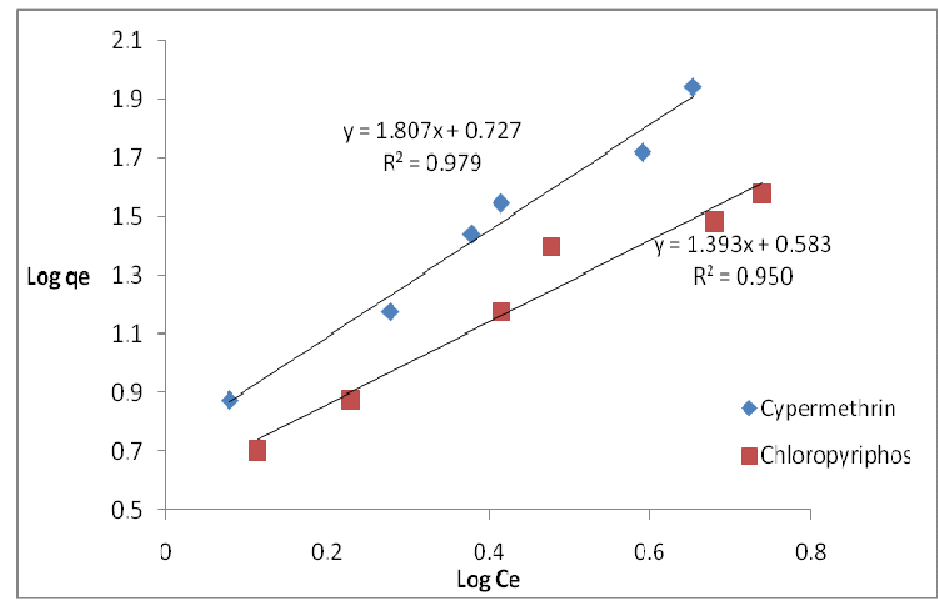

Fig 2: Freundlich adsorption of isotherm of cypermethrin and chloropyriphos adsorption

Table 5: Isotherm constants for cypermethrin and chloropyrophos adsorption

\begin{tabular}{clcll}
\hline \multicolumn{1}{c}{ Pesticide } & \multicolumn{2}{c}{ Freundlich } & \multicolumn{2}{c}{ Langmuir } \\
\hline cypermethrin & $\mathrm{R}^{2}$ & 0.979 & $\mathrm{R}^{2}$ & 0.973 \\
& $\mathrm{~K}_{\mathrm{f}}$ & 9.53 & $\mathrm{~K}_{\mathrm{L}}$ & 0.454 \\
& $\mathrm{n}$ & 5.33 & $\mathrm{q}_{\mathrm{m}}$ & 7.14 \\
chloropyrophos & $\mathrm{R}^{2}$ & 0.950 & $\mathrm{R}^{2}$ & 0.965 \\
& $\mathrm{~K}_{\mathrm{f}}$ & 8.91 & $\mathrm{~K}_{\mathrm{L}}$ & 0.974 \\
& $\mathrm{n}$ & 3.83 & $\mathrm{q}_{\mathrm{m}}$ & 4.93 \\
\hline
\end{tabular}

Conclusion: In this study the feasibility of curcas shell for the adsorption of cypermethrin and application of the activated carbon from jatropha Chloropyriphos adsorption was established.The 
adsorption depends on $\mathrm{pH}$,contact time, mass of the sample and initial concentration of the pesticide. The adsorption process of cypermethrin and Chloropyriphos fits better on Freundlich and Langmuir isotherms respectively.

\section{REFERENCES}

Abdessalem, AK; Bellakhal, N; Dachraoui M; Oturan MA (2010). "Treatment of a mixture of three pesticides by photo- and electro-Fenton processes". Desalination, 250, 450-455 492.

Chang, K; Lin, J;Chen S (2011). “Adsorption Studies on the Removal of Pesticides (Carbofuran) using Activated Carbon from Rice Straw Agricultural Waste", World Academy of science, Engineering and Technology, Vol:5, 317-320.

Chen, S; Sun, DZ; Chung, JS (2007. Treatment of pesticide wastewater by moving-bed biofilm reactor combined with Fenton-coagulation pretreatment, J Hazard Mater, 144 577-584.

Ignatoweiz, T; Toweel, G (2009)."Selection of sorbent for removing pesticides during water treatment". J. Hazard Mater. 169. 953-957.

Ma, YF; Sung, FT; JG; Lin BM (2010). Degradation of carbofuran in aqueous solution by ultrasound and Fenton processes: Effect of system parameters and kinetic study, J. Hazard Mater, 178 320-325.

Manuel Fernando, RF; Pereira Samanta, JMO; Soares Jose, LR; Figureueiredo A (2003). Carbon, 41, 811

Memon, GZ; Bhanger, MI; Akhtar, KT (2007) The removal efficiency of chestnut shells for selected pesticides from aqueous solutions, $J$ Colloid Interf Sci, 315 33-40.

Mirjana, BN;Rada. DP; Mila, DL. (2010) "Removal of organochlorine pesticides from water using virgin and regenerated granular activated carbon”, J. Serb. Chem. Soc. 75 (4) 565-573.
Jain, N; Josh, HH; Dutta, S.C; Kuma, RS; Panthak, H (2008). Biosorptrion of Copper from Waste Water using jatrophas seed coat, J. of Scientific and Industrial Research, vol. 67154-160

Okeola, OF; Odebunmi EO; Bakare OF, (2014): "Equilibrium and Kinetics Studies of Adsorption of Congo red by Activated Carbon prepared from Thevetia peruvianna shell", J. of Raw Material Research

Okeola, FO; Odebunm,i EO (2010). "Comparison of Freundlich and Langmuir Isotherms for Adsorption of Methylene Blue by Agrowaste Derived Activated Carbon", Advances in Natural and Applied Science, 4(3), 281-288.

Okeola, OF; Odebunmi EO; Ameen OM; Adebayo GB (2011). "Adsorption of Iron (III) ion Aqueous Solution Using Jatrophacurcas Seed Coat Activated Carbon", Proceedings of the $34^{\text {th }}$ Annual International Conference of the Chemical Society of Nigeria,

Salman, JM; Hammeed BH (2010). Removal of insecticide carboforan from aquoeous solutions by banana stalk activated carbon J. Harzard Mater, 176, 814-819

Singh, DK; Rao, SD; and Kaate, HK (2008). Biodegradation and bioremediation of pesticide in soil: concept, method and recent developments, Indian J Microbiol, 48 35-40.

Udeozor, SO; Evbuomwan, BO (2014). The effectiveness of snail shell as adsorbent for the treatment of waste water from beverage industries using $\mathrm{H}_{3} \mathrm{PO}_{4}$ as activating agent, $J$ of Engieering, Vol. 04, ISSN (p): 2278-8719

USEPA, U.S. Environmental protection Agency (2002), Revised Preliminary Human Health Risks Assessment for Atrazine Office of Pesticide Programs. Washington 